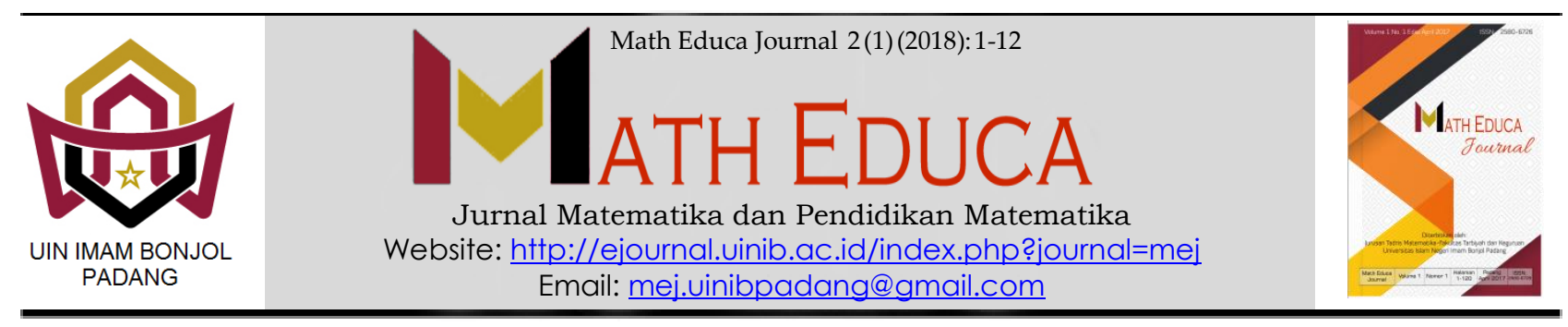

\title{
ANALISIS SOAL UJIAN TENGAH SEMESTER MATEMATIKA KELAS VII TINGKAT SMP NEGERI DI KOTA PADANG TAHUN AJARAN 2016/2017
}

\author{
Nana Sepriyanti ${ }^{1}$, Riadil Jannah ${ }^{2}$, Milya Sari $^{3}$ \\ ${ }^{1,2,3}$ Tadris Matematika, Tarbiyah dan Keguruan UIN IB Padang \\ Email: ${ }^{1}$ munzilatululya@yahoo.com, ${ }^{2}$ riadiljannah29@gmail.com
}

Received: January 2018; Accepted: March 2018; Published: April 2018

\begin{abstract}
Abstrak
Tujuan dari penelitian ini adalah mengetahui kualitas soal UTS matematika kelas VII tingkat SMP Negeri di Kota Padang tahun ajaran 2016/2017 ditinjau dari aspek validitas logis, validitas empiris, reliabilitas, tingkat kesukaran, daya beda dan distraktor soal. Penelitian ini merupakan penelitian deskriptif dengan dua pendekatan yaitu pendekatan kualitatif dan pendekatan kuantitatif. Pendekatan kualitatif digunakan untuk mengetahui validitas logis soal, sedangkan pendekatan kuantitatif digunakan untuk mengetahui validitas empiris, reliabilitas, tingkat kesukaran, daya pembeda dan distraktor soal. Hasil penelitian ini menunjukkan bahwa kualitas soal yang ditinjau dari analisis validitas logis soal UTS matematika kelas VII tingkat SMP Negeri di Kota Padang tahun ajaran 2016/2017 terdapat 2 soal tidak valid, 7 soal memiliki validitas sedang dan 31 soal dengan validitas tinggi, sedangkan kualitas validitas empiris soal adalah 0,49 dengan interpretasi validitas empiris tergolong sedang. Kualitas reliabilitas soal UTS matematika kelas VII tingkat SMP Negeri di Kota Padang tahun ajaran 2016/2017 adalah 0,64 dengan interpretasi reliabilitas tergolong cukup. Kualitas tingkat kesukaran soal UTS kelas VII tingkat SMP Negeri di Kota Padang tahun ajaran 2016/2017 terdapat: 6 soal tergolong mudah, 30 soal tergolong sedang, 4 soal tergolong sukar. Kualitas daya beda soal UTS matematika kelas VII tingkat SMP Negeri di Kota Padang tahun ajaran 2016/2017 terdapat: 10 soal memiliki daya pembeda kurang baik, 14 soal memiliki daya pembeda cukup, 9 soal memiliki daya pembeda baik, 7 soal memiliki daya pembeda sangat baik. Distraktor soal UTS matematika kelas VII tingkat SMP Negeri di Kota Padang tahun ajaran 2016/2017 diketahui sebanyak 30\% distraktor belum berfungsi dan perlu direvisi, 70\% distraktor lainnya sudah dapat berfungsi.
\end{abstract}

Kata kunci: validitas, reliabilitas, tingkat kesukaran, daya beda, distraktor.

\begin{abstract}
The purpose of this research is to know the quality mid term of math class VII SMP Negeri in Padang City academic year 2016/2017 when viewed from aspects of logical validity, empirical validity, reliability, difficulty, differentiation and distractor problems. This research is a descriptive research with two approaches that is qualitative approach and quantitative approach. Qualitative approach is used to find out the logical validity of the problem, while the quantitative approach is used to determine the empirical validity, reliability, difficulty level, distinguishing power and distractor problems. The results of this study indicate that the quality of items in terms of the analysis of logical validity about mid term of math class VII SMP Negeri in Padang City academic year 2016/2017 there are 2 invalid questions, 7 questions have medium validity and 31 questions with high validity. The quality of empirical validity about mid term of math class VII SMP Negeri in Padang City academic year 2016/2017 is 0.49 with interpretation of empirical validity is moderate. Quality of reliability about mid term of math class VII SMP Negeri in Padang City academic year 2016/2017 is 0.63 with the interpretation of reliability is quite enough. Levels of difficulty about mid term of math class VII SMP Negeri in padang at study year 2016/2017
\end{abstract}

\footnotetext{
${ }^{*}$ Corresponding author.

Peer review under responsibility UIN Imam Bonjol Padang.

(c) 2018 UIN Imam Bonjol Padang. All rights reserved. 
of 40 problems there are: 6 problems are relatively easy, 30 questions are classified as moderate, 4 the problem is quite difficult. The different power of mathematics mid term of math class VII SMP Negeri in Padang City academic year 2016/2017 from the 40 item is classified into; 14 items of the test have low power different, 13 items of the test have middle power different, 4 items test have high power different, and 9 items of the test have very good power different. From the distractor of mathematics mid term of math class VII SMP Negeri in Padang City academic year 2016/2017 can be as much 30\% distraktor can't yet function and needs to be revised, because is still qualified bad and very bad, meanwhile $70 \%$ another distraktor can function.

Keywords: validity, reliability, levels of difficulty, different power, distractor

\section{PENDAHULUAN}

Penelitian ini dilatarbelakangi oleh ditemukannya instrumen tes yang digunakan untuk mengukur kemampuan peserta didik belum memenuhi kriteria instrument tes yang baik, dikarenakan tidak dilakukan analisis terhadap instrument tes sebelum diujikan kepada peserta didik. Tes yang disusun harus memenuhi syarat atau ciri-ciri kualitas tes yang baik. Arikunto (2008:57) mengemukakan: "Sebuah tes yang dapat dikatakan baik sebagai alat pengukur harus memenuhi persyaratan tes, yaitu memiliki: Validitas, Reliabilitas, Objektivitas, Praktikabilitas dan Ekonomis". Syarat tersebut juga disetujui oleh Sukardi (2011:8) dengan menambahkan: membedakan, norma, fair dan taraf kesukaran, daya beda. Apabila setelah dianalisa tingkat kesukaran, daya pembeda, distaktor, validitas dan reabilitas tersebut baik maka tes tersebut sudah memiliki kualitas tes yang baik dan tinggi. Oleh karena itu tes yang digunakan untuk evaluasi haruslah memenuhi kriteria tes yang baik yaitu: validitas, reliabilitas, Objektivitas, Praktikabilitas dan Ekonomis. Jika tes yang digunakan untuk mengukur hasil belajar siswa harus berkualitas baik dan tinggi, maka perlu diketahui bagaimanakah kualitas soal yang digunakan untuk mengukur kemampuan peserta didik selama ini, apakah sudah sesuai dengan kriteria soal yang baik atau belum.

Kualitas soal yang digunakan untuk mengukur kemampuan peserta didik selama ini masih banyak yang belum memenuhi kriteria tes atau alat evaluasi yang baik. Hal ini dibuktikan dengan ditemukannya soal pilihan ganda pada mata pelajaran matematika kelas VII SMPN 9 Banda Aceh dengan 40\% berkategori sangat rendah, tingkat reliabilitas rendah, 28\% soal dengan kategori sukar, dan $24 \%$ soal tingkat kesukarannya sangat jelek (Suryawati dan Yulfikar, 2012). Ditemukan juga 9\% soal dengan kategori jelek, 6\% soal distraktornya tidak efektif pada mata pelajaran matematika kelas VII SMPN Baubau (Amrin dan Busnawir, 2014).

Pada penelitian lain ditemukan 3 butir soal dengan kategori sukar, 4 butir soal dengan validitas sangat rendah, $40 \%$ sola distraktornya tidak berfungsi dengan baik pada soal Ujian Nasional mata pelajaran matematika siswa SMPN di Kabupaten Buton Utara tahun 2011/2012 (Aliati dan Ibrahim, 2013). Hal yang sama juga terjadi dan ditemukan oleh Supandi dan Farikhah (2014), ditemukan 30\% soal tidak valid, $10 \%$ soal dengan kategori sukar pada instrument uji coba materi segitiga. Begitupula dengan yang ditemukan oleh Mutmainah (2012) 
Analisis Soal Ujian.... (Nana Sepriyanti, Riadil Jannah, Milya Sari) 3

$44 \%$ soal tidak valid, $41 \%$ soal berkategori jelek.

Untuk kualitas soal matematika buatan guru dikota padang juga telah diadakan penelitian oleh dosen Fakultas Tarbiyah dan Keguruan yang mengajar pada jurusan matematika, dimana hasil penelitian untuk kualitas soal matematika tingkat SD/MI se Kota Padang masih kurang dan masih banyak kesalahan dalam pembuatan soal (Eliza dkk, 2013). Adapun penyebab rendahnya kualitas soal pada beberapa penelitian tersebut disebabkan karena soal hannya dibuat oleh satu orang guru, tanpa didiskusikan dengan guru lain yang mengajar mata pelajaran yang sama.

Berdasarkan kualitas soal yang kurang baik tersebut maka guru di Kota Padang mencoba meminimalis peluang terjadinya pembuatan soal yang kurang baik dengan mengadakan pembuatan soal secara bersamasama dalam Musyawarah Guru Mata Pelajaran (MGMP) matematika Kota Padang.

Berdasarkan keterangan dari seorang guru matematika MGMP Kota Padang, pembuatan soal UTS dilakukan ketika waktu pelaksanaan UTS sudah semakin dekat, pembuatan soal diawali dengan menyepakati Kompetensi Inti dan Kompetensi Dasar yang akan di ujikan pada UTS, dan dilanjutkan dengan pembentukan SKL. Setelah itu barulah guru MGMP merancang soal serta menyediakan kunci jawaban masing-masing soal. Soal hannya divalidasi secara bersama-sama oleh guru MGMP, soal diujikan tanpa dilakukan uji coba sebelum soal di finalisasi sebagai soal UTS. Setelah soal disusun berdasarkan kesepakatan guru MGMP maka soal dikirim ketempat pengetikan yang ditentukan oleh Dinas Pendidikan Kota Padang untuk dicetak dan dikemas langsung agar dapat di sebarkan kepada sekolah.

Untuk mengetahui kualitas soal UTS Matematika buatan guru MGMP maka akan dilakukan analisis terhadap soal matematika buatan guru MGMP, dengan menjadikan SMPN 31 Padang sebagai sampel, dikarenakan SMPN 31 Padang terdapat pada urutan ke delapan di kota padang, sudah terakreditasi A, berstandar nasional. Dilakukannya analisis terhadap soal UTS matematika buatan guru MGMP ini agar diketahui apakah soal tersebut sudah memenuhi aspek validitas, reliabilitas, tingkat kesukaran dan daya beda soal serta distraktor sudah efektif atau belum. Sehingga diketahui butir-butir soal yang sudah berkualitas baik, kurang baik dan yang berkualitas jelek pada soal matematika UTS SMPN di kota Padang. Diharapkan hasil penelitian ini dapat dipergunakan oleh guru MGMP matematika dalam penulisan soal ujian akhir semester (UAS), sehingga kesalahan pada soal matematika UTS tidak terulang pada pembuatan soal UAS dan UTS pada semester selanjutnya. Berdasarkan permasalahan yang ditemukan ketika UTS matematika kelas VII dilaksanakan dan berdasarkan hasil penelitian sebelumnya maka perlu dilakukan penelitian tentang Analisis Soal Ujian Tengah Semester Matematika Kelas VII Tingkat SMP Negeri di Kota Padang.

\section{METODE PENELITIAN}

\section{Jenis Penelitian}

Penelitian ini merupakan penelitian deskriptif dengan dua pendekatan yaitu pendekatan kualitatif dan pendekatan kuantitatif. 


\section{Waktu dan Tempat Penelitian}

Penelitian ini dilakukan di SMP N 31

Padang. Penelitian dilakukan setelah dilaksanakannya UTS genap mata pelajaran matematika, penelitian dilaksanakan pada tanggal 9-20 Juni 2017.

\section{Populasi dan Sampel}

Populasi dalam penelitian ini adalah seluruh peserta didik kelas VII tingkat SMP Negeri di Kota Padang tahun ajaran 2016/2017, bagian dari populasi pada penelitian ini adalah seluruh peserta didik kelas VII SMPN 31 Padang. Sampel pada penelitian ini adalah peserta didik kelas VII dengan kemapuan: tinggi, sedang dan rendah. Teknik yang digunakan dalam pengambilan sampel pada penelitian ini adalah teknik purposive sampling, yaitu penentuan sampel dengan pertimbangan/tujuan tertentu (Sugiono, 2012:124). Sampel pada penelitian ini adalah kelas $V I I_{1}$ (sampel peserta didik berkemampuan tinggi), $V I I_{4}$ (sampel peserta didik berkemampuan sedang), $\mathrm{VII}_{8}$ (sampel peserta didik berkemampuan rendah). Kelas yang dijadikan sampel diharapkan dapat mewakili peserta didik SMP Negeri di Kota Padang. Pengambilan sampel pada penelitian ini ditentukan berdasarkan informasi dan saran oleh Ibu Roswita S.Pd selaku guru matematika kelas VII SMP N 31 Padang.

\section{Prosedur}

1. Tahap Persiapan, yaitu : Observasi ke sekolah tempat penelitian, Mengamati langsung proses UTS mata pelajaran matematika kelas VII berlangsung di sekolah yang dijadikan tempat penelitian, Mengurus surat izin penelitian ke Fakultas Tarbiyah IAIN Imam Bonjol Padang, Mempersiapkankan instrumen pengumpulan data berupa tes lembar telaah soal, khususnya instrument untuk uji validitas soal.

\section{Tahap Pelaksanaan}

a) Memahami dan memasuki lapangan

b) Pengumpulan Data

Pengumpulan data dilakukan dengan mengumpulkan dokumentasi UTS matematika kelas VII SMP N 31 Padang berupa: SKL, soal ujian, lembar jawaban peserta didik, dan kunci jawaban UTS mata pelajaran matematika kelas VII. Data diambil dengan jalan interview dengan guru yang bersangkutan setelah tes selesai dilaksanakan.

c) Menentukan kelas yang akan dijadikan subjek penelitian.

d) Menentukan kelompok peserta didik berdasarkan kemampuan peserta didik, ditentukan berdasarkan nilai UTS, sehingga diperoleh peserta didik kelompok atas (KA), peserta didik kelompok tengah (KT), dan peserta didik kelompok bawah (KB).

\section{Tahap Penyelesaian}

a. Melakukan analisis terhadap soal matematika dari segi validitas, reliabilitas, tingkat kesukaran dan daya beda soal, serta fungsi distraktor.

b. Melakukan pembahasan dan menarik kesimpulan dari hasil analisis data, yaitu menyimpulkan tingkat validitas, reliabilitas, tingkat kesukaran, daya beda soal dan distraktor. 
Analisis Soal Ujian.... (Nana Sepriyanti, Riadil Jannah, Milya Sari) 5

c. Menyusun laporan hasil penelitian, meliputi validitas butir soal, reliabilitas, daya menuliskan soal yang berkualitas baik, sedang dan kurang baik.

\section{Data, Intrumen, dan Teknik Pengumpulan} Data

1) Data Kualitatif

Data kualitatif dalam penelitian ini adalah lembar telaah soal yang telah diisi oleh 3 orang panelis yang digunakan untuk uji validitas logis soal.

2) Data Kuantitatif

Data kuantitatif pada penelian ini berupa lembar jawaban dan skor UTS matematika peserta didik kelas VII SMPN 31 Padang yang digunakan untuk uji validitas empiris, reliabilitas, tingkat kesukaran, daya beda dan distraktor soal.

Sumber data (data sekunder) dalam penelitian ini adalah 3 (tiga) orang panelis dan seorang guru mata pelajaran matematika kelas VII dan wakil kesiswaan SMP N 31 Padang. Dalam penelitian ini teknik yang digunakan dalam pengumpulan data adalah dokumentasi. Dokumentasi pada penelitian ini berupa soal UTS mata pelajaran matematika, kunci jawaban, lembar jawaban peserta didik dan SKL soal UTS matematika kelas VII SMP Negeri di Kota Padang tahun ajaran 2016/2017.

\section{Teknik Analisis Data}

Analisis butir soal dilakukan secara manual yaitu dengan menggunakan rumus analisis butir soal dan menggunakan program Anates. Anates merupakan sebuah program aplikasi komputer yang bertujuan untuk menganalisis kualitas butir soal. Pengolahan data yang dapat dilakukan dengan program Anates 
Tabel 1. Kualitas Validitas Empiris Soal

\begin{tabular}{|c|c|c|c|c|c|c|c|c|c|}
\hline & \multicolumn{3}{|c|}{$\begin{array}{l}\text { Banyak } \\
\text { Aspek } \\
\text { Tidak } \\
\text { Sesuai }\end{array}$} & \multirow[t]{2}{*}{$\begin{array}{l}\text { Vali } \\
\text { ditas }\end{array}$} & \multirow[t]{2}{*}{ No } & \multicolumn{3}{|c|}{$\begin{array}{c}\text { Banyak } \\
\text { Aspek } \\
\text { Tidak } \\
\text { Sesuai }\end{array}$} & \multirow[t]{2}{*}{$\begin{array}{l}\text { Vali } \\
\text { ditas }\end{array}$} \\
\hline & 1 & 2 & 3 & & & 1 & 2 & 3 & \\
\hline 1 & 1 & - & - & Sedang & 21 & - & - & - & Tinggi \\
\hline 2 & - & - & - & Tinggi & 22 & - & - & - & Tinggi \\
\hline 3 & - & - & - & Tinggi & 23 & - & 1 & - & $\begin{array}{l}\text { Tidak } \\
\text { Valid }\end{array}$ \\
\hline 4 & - & - & - & Tinggi & 24 & - & 1 & - & Sedang \\
\hline 5 & - & - & - & Tinggi & 25 & - & - & - & Tinggi \\
\hline 6 & - & - & - & Tinggi & 26 & - & 1 & - & Sedang \\
\hline 7 & - & - & - & Tinggi & 27 & - & 1 & - & Sedang \\
\hline 8 & - & - & - & Tinggi & 28 & - & - & - & Tinggi \\
\hline 9 & - & 1 & - & Sedang & 29 & - & 1 & - & Sedang \\
\hline 10 & - & - & - & Tinggi & 30 & - & - & - & Tinggi \\
\hline 11 & - & - & - & Tinggi & 31 & - & - & - & Tinggi \\
\hline 12 & - & - & - & Tinggi & 32 & 1 & - & - & $\begin{array}{l}\text { Tidak } \\
\text { Valid }\end{array}$ \\
\hline 13 & - & - & - & Tinggi & 33 & - & - & - & Tinggi \\
\hline 14 & - & 1 & - & Sedang & 34 & - & - & - & Tinggi \\
\hline 15 & - & - & - & Tinggi & 35 & - & - & - & Tinggi \\
\hline 16 & - & - & - & Tinggi & 36 & - & - & - & Tinggi \\
\hline 17 & - & - & - & Tinggi & 37 & - & - & - & Tinggi \\
\hline 18 & - & - & - & Tinggi & 38 & - & - & - & Tinggi \\
\hline 19 & - & - & - & Tinggi & 39 & - & - & - & Tinggi \\
\hline 20 & - & - & - & Tinggi & 40 & - & - & - & Tinggi \\
\hline
\end{tabular}

Berdasarkan Tabel 1 soal UTS Matematika kelas VII tingkat SMP Negeri di Kota Padang dilihat dari validitas logis terdapat 2 soal tidak valid, 7 soal memiliki validitas sedang dan 31 soal dengan validitas tinggi.

Kesimpulan terhadap butir soal yang telah ditelaah, dapat ditentukan dengan kriteria sebagai berikut (Syahrial, 2002:53):

1) Memiliki kadar validitas tinggi jika butir soal yang memenuhi semua kriteria pada aspek materi, konstruksi, dan bahasa.

2) Memiliki kadar validitas sedang jika butir soal setidak-tidaknya memenuhi aspek materi: a) butir soal sesuai dengan indikator, dan b) isi materi sesuai dengan tujuan pengukuran, serta sebanyak-banyaknya hanya ada tiga kriteria pada aspek konstruksi dan satu kriteria pada aspek bahasa yang tidak terpenuhi.
3) Memiliki kadar validitas rendah jika butir soal tidak memenuhi semua kriteria pada aspek materi a) butir soal sesuai dengan indikator, dan b) isi materi sesuai dengan tujuan pengukuran, lebih dari tiga kriteria pada aspek konstruksi, dan lebih dari satu kriteria pada aspek bahasa.

Tabel 2. Validitas Empiris Soal Validitas Empiris Soal

\begin{tabular}{llll}
$\begin{array}{c}\text { Kelas } \\
\boldsymbol{V I I}_{\mathbf{1}}\end{array}$ & \multicolumn{1}{c}{ Kelas } & \multicolumn{1}{c}{ Kelas } & \multicolumn{1}{c}{ Kesimpulan } \\
$\boldsymbol{V I I}_{\mathbf{4}}$ & \\
\hline 0,74 & 0,45 & 0,28 & 0,49 \\
(Tinggi) & (Cukup) & (Rendah) & (cukup) \\
\hline
\end{tabular}

Validitas empiris soal dapat diketahui menggunakan korelasi product-moment (Arikunto, 2009:72); (Arifin, 2013:254):

$$
\begin{aligned}
& r_{x y}=r_{\frac{11}{22}} \\
& =\frac{N \sum X Y-\left(\sum X\right)\left(\sum Y\right)}{\sqrt{\left\{N \sum X^{2}-\left(\sum X\right)^{2}\right\}\left\{N \sum Y^{2}-\left(\sum Y\right)^{2}\right\}}}
\end{aligned}
$$

Dari Tabel 2 dapat ditentukan validitas empiris rata-rata dari ketiga kelas, dan disimpulkan bahwa kualitas validitas empiris soal UTS Matematika kelas VII tingkat SMP Negeri di Kota Padang adalah 0,49 dengan interpretasi validitas empiris tergolong sedang.

Soal UTS matematika kelas VII tingkat SMP Negeri di Kota Padang dinilai sudah dapat digunakan sebagai instrument pengukur kemampuan peserta didik, Karena sudah memenuhi salah satu kriteria tes yang baik dengan memiliki interpretasi validitas empiris tergolong sedang. Hal ini sesuai dengan pendapat Arikunto (2008:57) yang mengemukakan Sebuah tes yang dapat dikatakan baik sebagai alat pengukur harus memenuhi 
persyaratan tes, yaitu memiliki Validitas. Sudijono (2011:93) juga menyatakan bahwa setidak-tidaknya ada empat ciri atau karakteristik yang harus dimiliki oleh suatu tes, dan satu diantaranya adalah memiliki validitas (kesahihan) yang cukup tinggi.

Tabel 3. Reliabilitas Soal

\begin{tabular}{lcll}
\hline \multicolumn{3}{c}{ Reliabilitas } & Kesimpulan \\
\multicolumn{1}{c}{$\boldsymbol{V} \boldsymbol{I I}_{\mathbf{1}}$} & \multicolumn{1}{c}{$\boldsymbol{V I I}_{\mathbf{4}}$} & \multicolumn{1}{c}{$\boldsymbol{V} \boldsymbol{I I}_{\mathbf{8}}$} & \\
\hline 0,85 & 0,62 & 0,44 & 0,64 \\
(Tinggi) & (Cukup) & (Cukup) & (Cukup) \\
\hline
\end{tabular}

Untuk mengubah koefisien reliabilitas setengah instrument menjadi koefisien reliabilitas penuh dilakukan dengan menggunakan Rumus Spearman Brown (Arikunto, 2012:107):

$$
r_{11}=\frac{2 \times r_{\frac{11}{22}}}{1+r_{\frac{11}{22}}}
$$

Berdasarkan Tabel 3 dapat ditentukan reliabilitas rata-rata dari ketiga kelas dan disimpulkan bahwa kualitas reliabilitas soal UTS Matematika kelas VII tingkat SMP Negeri di Kota Padang adalah 0,63 dengan interpretasi reliabilitas tergolong cukup.

Soal UTS matematika kelas VII tingkat SMP Negeri di Kota Padang dinilai sudah dapat digunakan sebagai instrument pengukur kemampuan peserta didik, Karena sudah memenuhi salah satu kriteria tes yang baik dengan memiliki interpretasi reliabilitas tergolong cukup. Hal ini sesuai dengan pendapat Hamzah (2014:100) yang mengemukakan Sebuah tes yang dapat dikatakan baik sebagai alat pengukur harus memenuhi persyaratan tes, yaitu memiliki reliabilitas.
Tabel 4. Tingkat Kesukaran Soal

\begin{tabular}{|c|c|c|c|c|}
\hline \multirow[b]{2}{*}{$\begin{array}{l}\text { No } \\
\text { Soal }\end{array}$} & \multicolumn{3}{|c|}{ Tingkat kesukaran } & \multirow[b]{2}{*}{ Kesimpulan } \\
\hline & $\begin{array}{l}\text { Kelas } \\
V I I_{1}\end{array}$ & $\begin{array}{c}\text { Kelas } \\
\mathrm{VII}_{4}\end{array}$ & $\begin{array}{c}\text { Kelas } \\
V I I_{8}\end{array}$ & \\
\hline 1 & Mudah & Sedang & Sedang & Sedang \\
\hline 2 & Mudah & Mudah & Mudah & Mudah \\
\hline 3 & Mudah & Sedang & Sedang & Mudah \\
\hline 4 & Sedang & Sukar & Sukar & Sukar \\
\hline 5 & Mudah & Sedang & Sedang & Sedang \\
\hline 6 & Mudah & Sedang & Sedang & Mudah \\
\hline 7 & Mudah & Mudah & Mudah & Sedang \\
\hline 8 & Mudah & Sedang & Sedang & Sedang \\
\hline 9 & Sedang & Mudah & Sedang & Sedang \\
\hline 10 & Sedang & Sukar & Sukar & Sedang \\
\hline 11 & Mudah & Mudah & Sedang & Mudah \\
\hline 12 & Sukar & Sedang & Sukar & Sedang \\
\hline 13 & Sedang & Sedang & Sedang & Sedang \\
\hline 14 & Sukar & Sukar & Sukar & Sukar \\
\hline 15 & Sukar & Sedang & Sedang & Sedang \\
\hline 16 & Mudah & Sedang & Sedang & Sedang \\
\hline 17 & Sedang & Mudah & Sukar & Sedang \\
\hline 18 & Mudah & Mudah & Sedang & Sedang \\
\hline 19 & Sukar & Sukar & Sukar & Sukar \\
\hline 20 & Sedang & Sedang & Sukar & Sedang \\
\hline 21 & Sedang & Sedang & Sedang & Sedang \\
\hline 22 & Sedang & Sedang & Sukar & Sedang \\
\hline 23 & Sukar & Sedang & Sedang & Sedang \\
\hline 24 & Sedang & Sedang & Sedang & Sedang \\
\hline 25 & Mudah & Mudah & Sedang & Sedang \\
\hline 26 & Sedang & Sukar & Sukar & Sukar \\
\hline 27 & Sedang & Sedang & Sedang & Sedang \\
\hline 28 & Mudah & Mudah & Mudah & Mudah \\
\hline 29 & Sedang & Sedang & Sedang & Sedang \\
\hline 30 & Sukar & Sedang & Sedang & Sedang \\
\hline 31 & Mudah & Mudah & Mudah & Mudah \\
\hline 32 & Sedang & Sukar & Sukar & Sedang \\
\hline 33 & Sedang & Mudah & Sedang & Sedang \\
\hline 34 & Sedang & Sedang & Sedang & Sedang \\
\hline 35 & Sukar & Sukar & Sedang & Sedang \\
\hline 36 & Sedang & Sedang & Sukar & Sedang \\
\hline 37 & Sedang & Sukar & Sedang & Sedang \\
\hline 38 & Mudah & Sedang & Sukar & Sedang \\
\hline 39 & Sedang & Sukar & Sedang & Sedang \\
\hline 40 & Mudah & Sedang & Sedang & Sedang \\
\hline
\end{tabular}

Analisis tingkat kesukaran soal matematika UTS kelas VII SMPN 31 Padang dapat diketahui dengan menggunakan Rumus sesuai pendapat Arikunto (2012:208); Sudijono (2012:372):

$$
P=\frac{B}{J S}
$$


Berdasarkan Tabel 4 dapat ditentukan tingkat kesukaran rata-rata setiap soal dan disimpulkan kualitas tingkat kesukatan soal UTS Matematika kelas VII tingkat SMP Negeri di Kota Padang, dimana dari 40 soal terdapat: 6 soal tergolong mudah, 30 soal tergolong sedang, 4 soal tergolong sukar.

Soal UTS matematika kelas VII tingkat SMP Negeri di Kota Padang dinilai sudah dapat digunakan sebagai instrument pengukur kemampuan peserta didik, Karena sebagian besar soal memiliki tingkat kesukaran yang baik, yaitu tidak terlalu sukar dan tidak pula terlalu mudah, hal ini sesuai dengan pendapat Sudijono (2011:370) yang mengemukakan bahwa butir-butir item tes hasil belajar dapat dinyatakan sebagai butir- butir item yang baik, apabila butir-butir item tersebut tidak terlalu sukar dan tidak pula terlalu mudah dengan kata lain derajat kesukaran item itu adalah sedang atau cukup.

Tabel 5. Daya Pembeda Soal

\begin{tabular}{|c|c|c|c|c|}
\hline $\begin{array}{l}\text { No } \\
\text { So } \\
\text { al }\end{array}$ & $\begin{array}{l}\text { Kelas } \\
V_{I} I_{1} \\
\text { Indeks } \\
\text { DP }\end{array}$ & $\begin{array}{l}\text { Kelas } \\
V_{I I} \\
\text { Indeks } \\
\text { DP }\end{array}$ & $\begin{array}{l}\text { Kelas } \\
V I I_{8} \\
\text { Indeks } \\
\text { DP }\end{array}$ & $\begin{array}{l}\text { Kesim } \\
\text { pulan }\end{array}$ \\
\hline 1 & $\begin{array}{l}\text { Sangat } \\
\text { Baik }\end{array}$ & Baik & $\begin{array}{l}\text { Kurang } \\
\text { Baik }\end{array}$ & Cukup \\
\hline 2 & $\begin{array}{l}\text { Sangat } \\
\text { Baik }\end{array}$ & $\begin{array}{l}\text { Kurang } \\
\text { Baik }\end{array}$ & $\begin{array}{l}\text { Kurang } \\
\text { Baik }\end{array}$ & Cukup \\
\hline 3 & Cukup & $\begin{array}{l}\text { Kurang } \\
\text { Baik }\end{array}$ & $\begin{array}{l}\text { Sangat } \\
\text { Baik }\end{array}$ & $\begin{array}{l}\text { Kurang } \\
\text { Baik }\end{array}$ \\
\hline 4 & $\begin{array}{l}\text { Kurang } \\
\text { Baik }\end{array}$ & $\begin{array}{l}\text { Kurang } \\
\text { Baik }\end{array}$ & Baik & $\begin{array}{l}\text { Kurang } \\
\text { Baik }\end{array}$ \\
\hline 5 & $\begin{array}{l}\text { Kurang } \\
\text { Baik }\end{array}$ & $\begin{array}{l}\text { Kurang } \\
\text { Baik }\end{array}$ & Baik & $\begin{array}{l}\text { Kurang } \\
\text { Baik }\end{array}$ \\
\hline 6 & $\begin{array}{l}\text { Kurang } \\
\text { Baik }\end{array}$ & $\begin{array}{l}\text { Sangat } \\
\text { Baik }\end{array}$ & $\begin{array}{l}\text { Sangat } \\
\text { Baik }\end{array}$ & Baik \\
\hline 7 & Cukup & $\begin{array}{l}\text { Sangat } \\
\text { Baik }\end{array}$ & $\begin{array}{l}\text { Sangat } \\
\text { Baik }\end{array}$ & $\begin{array}{l}\text { Sangat } \\
\text { Baik }\end{array}$ \\
\hline 8 & $\begin{array}{l}\text { Kurang } \\
\text { Baik }\end{array}$ & Cukup & Cukup & $\begin{array}{l}\text { Kurang } \\
\text { Baik }\end{array}$ \\
\hline 9 & $\begin{array}{l}\text { Kurang } \\
\text { Baik }\end{array}$ & $\begin{array}{l}\text { Sangat } \\
\text { Baik }\end{array}$ & Baik & Tinggi \\
\hline
\end{tabular}

\begin{tabular}{|c|c|c|c|c|}
\hline 10 & $\begin{array}{l}\text { Sangat } \\
\text { Baik }\end{array}$ & Baik & $\begin{array}{l}\text { Sangat } \\
\text { Baik }\end{array}$ & $\begin{array}{l}\text { Sangat } \\
\text { Baik }\end{array}$ \\
\hline 11 & Baik & Sangat & Sangat & Sangat \\
\hline 12 & Kurang & $\begin{array}{l}\text { Baik } \\
\text { Kurang }\end{array}$ & $\begin{array}{l}\text { Baik } \\
\text { Kurang }\end{array}$ & $\begin{array}{l}\text { Baik } \\
\text { Kurang }\end{array}$ \\
\hline & Baik & Baik & Baik & Baik \\
\hline 13 & Cukup & $\begin{array}{l}\text { Sangat } \\
\text { Baik }\end{array}$ & $\begin{array}{l}\text { Kurang } \\
\text { Baik }\end{array}$ & Baik \\
\hline 14 & Cukup & $\begin{array}{l}\text { Kurang } \\
\text { Baik }\end{array}$ & Baik & $\begin{array}{l}\text { Kurang } \\
\text { Baik }\end{array}$ \\
\hline 15 & Baik & $\begin{array}{l}\text { Sangat } \\
\text { Baik }\end{array}$ & $\begin{array}{l}\text { Kurang } \\
\text { Baik }\end{array}$ & Baik \\
\hline 16 & $\begin{array}{l}\text { Kurang } \\
\text { Baik }\end{array}$ & $\begin{array}{l}\text { Sangat } \\
\text { Baik }\end{array}$ & $\begin{array}{l}\text { Sangat } \\
\text { Baik }\end{array}$ & Baik \\
\hline 17 & $\begin{array}{l}\text { Sangat } \\
\text { Baik }\end{array}$ & Cukup & $\begin{array}{l}\text { Kurang } \\
\text { Baik }\end{array}$ & Cukup \\
\hline 18 & Baik & Cukup & $\begin{array}{l}\text { Sangat } \\
\text { Baik }\end{array}$ & Baik \\
\hline 19 & Cukup & $\begin{array}{l}\text { Kurang } \\
\text { Baik }\end{array}$ & Cukup & $\begin{array}{l}\text { Kurang } \\
\text { Baik }\end{array}$ \\
\hline 20 & Baik & $\begin{array}{l}\text { Sangat } \\
\text { Baik }\end{array}$ & Cukup & Baik \\
\hline 21 & $\begin{array}{l}\text { Sangat } \\
\text { Baik }\end{array}$ & $\begin{array}{l}\text { Sangat } \\
\text { Baik }\end{array}$ & Cukup & $\begin{array}{l}\text { Sangat } \\
\text { Baik }\end{array}$ \\
\hline 22 & $\begin{array}{l}\text { Sangat } \\
\text { Baik }\end{array}$ & $\begin{array}{l}\text { Sangat } \\
\text { Baik }\end{array}$ & Cukup & Baik \\
\hline 23 & $\begin{array}{l}\text { Kurang } \\
\text { Baik }\end{array}$ & $\begin{array}{l}\text { Kurang } \\
\text { Baik }\end{array}$ & Baik & $\begin{array}{l}\text { Kurang } \\
\text { Baik }\end{array}$ \\
\hline 24 & $\begin{array}{l}\text { Sangat } \\
\text { Baik }\end{array}$ & $\begin{array}{l}\text { Kurang } \\
\text { Baik }\end{array}$ & $\begin{array}{l}\text { Kurang } \\
\text { Baik }\end{array}$ & Cukup \\
\hline 25 & Cukup & $\begin{array}{l}\text { Sangat } \\
\text { Baik }\end{array}$ & $\begin{array}{l}\text { Sangat } \\
\text { Baik }\end{array}$ & $\begin{array}{l}\text { Sangat } \\
\text { Baik }\end{array}$ \\
\hline 26 & $\begin{array}{l}\text { Kurang } \\
\text { Baik }\end{array}$ & $\begin{array}{l}\text { Kurang } \\
\text { Baik }\end{array}$ & $\begin{array}{l}\text { Kurang } \\
\text { Baik }\end{array}$ & $\begin{array}{l}\text { Kurang } \\
\text { Baik }\end{array}$ \\
\hline 27 & Cukup & $\begin{array}{l}\text { Sangat } \\
\text { Baik }\end{array}$ & $\begin{array}{l}\text { Kurang } \\
\text { Baik }\end{array}$ & Cukup \\
\hline 28 & $\begin{array}{l}\text { Kurang } \\
\text { Baik }\end{array}$ & Baik & Cukup & Cukup \\
\hline 29 & $\begin{array}{l}\text { Sangat } \\
\text { Baik }\end{array}$ & $\begin{array}{l}\text { Sangat } \\
\text { Baik }\end{array}$ & $\begin{array}{l}\text { Kurang } \\
\text { Baik }\end{array}$ & $\begin{array}{l}\text { Sangat } \\
\text { Baik }\end{array}$ \\
\hline 30 & $\begin{array}{l}\text { Sangat } \\
\text { Baik }\end{array}$ & $\begin{array}{l}\text { Kurang } \\
\text { Baik }\end{array}$ & $\begin{array}{l}\text { Sangat } \\
\text { Baik }\end{array}$ & Cukup \\
\hline 31 & Rendah & Cukup & $\begin{array}{l}\text { Sangat } \\
\text { Baik }\end{array}$ & Cukup \\
\hline 32 & $\begin{array}{l}\text { Sangat } \\
\text { Baik }\end{array}$ & Cukup & $\begin{array}{l}\text { Kurang } \\
\text { Baik }\end{array}$ & Cukup \\
\hline 33 & $\begin{array}{l}\text { Sangat } \\
\text { Baik }\end{array}$ & $\begin{array}{l}\text { Sangat } \\
\text { Baik }\end{array}$ & $\begin{array}{l}\text { Kurang } \\
\text { Baik }\end{array}$ & Cukup \\
\hline 34 & $\begin{array}{l}\text { Sangat } \\
\text { Baik }\end{array}$ & $\begin{array}{l}\text { Sangat } \\
\text { Baik }\end{array}$ & Cukup & $\begin{array}{l}\text { Sangat } \\
\text { Baik }\end{array}$ \\
\hline 35 & $\begin{array}{l}\text { Sangat } \\
\text { Baik }\end{array}$ & $\begin{array}{l}\text { Kurang } \\
\text { Baik }\end{array}$ & Cukup & Cukup \\
\hline 36 & $\begin{array}{l}\text { Sangat } \\
\text { Baik }\end{array}$ & $\begin{array}{l}\text { Sangat } \\
\text { Baik }\end{array}$ & $\begin{array}{l}\text { Kurang } \\
\text { Baik }\end{array}$ & Cukup \\
\hline
\end{tabular}


Analisis Soal Ujian.... (Nana Sepriyanti, Riadil Jannah, Milya Sari) 9

\begin{tabular}{|c|c|c|c|c|}
\hline 37 & $\begin{array}{l}\text { Sangat } \\
\text { Baik }\end{array}$ & $\begin{array}{l}\text { Kurang } \\
\text { Baik }\end{array}$ & Cukup & Baik \\
\hline 38 & Baik & Baik & $\begin{array}{l}\text { Kurang } \\
\text { Baik }\end{array}$ & Cukup \\
\hline 39 & $\begin{array}{l}\text { Sangat } \\
\text { Baik }\end{array}$ & $\begin{array}{l}\text { Kurang } \\
\text { Baik }\end{array}$ & $\begin{array}{l}\text { Kurang } \\
\text { Baik }\end{array}$ & $\begin{array}{l}\text { Kurang } \\
\text { Baik }\end{array}$ \\
\hline 40 & Cukup & Baik & Baik & Cukup \\
\hline
\end{tabular}

Indeks/daya pembeda soal diperoleh dengan menggunakan rumus dari Depdiknas Kota Padang (2017) yaitu:

$$
D B=\frac{B A-B B}{\frac{1}{2} N}
$$

Kesimpulan daya pembeda soal ditentukan dengan menghitung nilai rata-rata daya pembeda dari masing-masing kelas, kemudian disimpulkan dengan menyesuaikan indeks daya pembeda soal.

Berdasarkan Tabel 5 dapat dilihat kualitas daya pembeda soal UTS Matematika kelas VII tingkat SMP Negeri di Kota Padang, dimana dari 40 soal terdapat: 10 soal memiliki daya pembeda kurang baik, 14 soal memiliki daya pembeda cukup, 9 soal memiliki daya pembeda baik, 7 soal memiliki daya pembeda sangat baik.

Soal UTS matematika kelas VII tingkat SMP Negeri di Kota Padang dinilai sudah dapat digunakan sebagai instrument pengukur kemampuan peserta didik, Karena sebagian besar soal dapat membedakan pesrta didik dengan kemampuan rendah, sedang dan tinggi, hal ini sesuai dengan pendapat Arikunto (2012:211) dan Sudijono (2011:385) yang berpendapat bahwa daya pembeda suatu soal adalah bagaimana kemampuan soal itu untuk membedakan siswa-siswa yang termasuk kelompok pandai (upper group) dengan siswa- siswa yang termasuk kelompok kurang (lower group).

Dari ketiga kelas diperoleh rata-rata kualitas distraktor soal UTS matematika kelas VII SMP Negeri di Kota Padang, dimana sebanyak $30 \%$ distraktor belum dapat berfungsi dan perlu direvisi, karena masih berkualitas jelek atau sangat jelek, sedangkan selebihnya (70\%) distraktor lainnya sudah dapat berfungsi.

\section{Tabel 6. Kualitas Soal}

\begin{tabular}{|c|c|c|c|}
\hline $\begin{array}{l}\text { No } \\
\text { Soal }\end{array}$ & $\begin{array}{c}\text { Tingkat } \\
\text { Kesukaran }\end{array}$ & $\begin{array}{l}\text { Daya } \\
\text { Beda }\end{array}$ & Keputusan \\
\hline 1 & Sedang & Cukup & Dipakai \\
\hline 2 & Mudah & Cukup & Dipakai \\
\hline 3 & Mudah & Rendah & Direvisi \\
\hline 4 & Sukar & Rendah & Dipakai \\
\hline 5 & Sedang & Rendah & Dipakai \\
\hline 6 & Mudah & Tinggi & Dipakai \\
\hline 7 & Sedang & $\begin{array}{l}\text { Sangat } \\
\text { Tinggi }\end{array}$ & Dipakai \\
\hline 8 & Sedang & Rendah & Dipakai \\
\hline 9 & Sedang & Tinggi & Dipakai \\
\hline 10 & Sedang & $\begin{array}{l}\text { Sangat } \\
\text { Tinggi }\end{array}$ & Dipakai \\
\hline 11 & Mudah & $\begin{array}{l}\text { Sangat } \\
\text { Tinggi }\end{array}$ & Dipakai \\
\hline 12 & Sedang & Rendah & Dipakai \\
\hline 13 & Sedang & Tinggi & Dipakai \\
\hline 14 & Sukar & Rendah & Dipakai \\
\hline 15 & Sedang & Tinggi & Dipakai \\
\hline 16 & Sedang & Tinggi & Dipakai \\
\hline 17 & Sedang & Cukup & Dipakai \\
\hline 18 & Sedang & Tinggi & Dipakai \\
\hline 19 & Sukar & Rendah & Dipakai \\
\hline 20 & Sedang & Tinggi & Dipakai \\
\hline 21 & Sedang & $\begin{array}{l}\text { Sangat } \\
\text { Tinggi }\end{array}$ & Dipakai \\
\hline 22 & Sedang & Tinggi & Dipakai \\
\hline 23 & Sedang & Rendah & Direvisi \\
\hline 24 & Sedang & Cukup & Dipakai \\
\hline 25 & Sedang & $\begin{array}{l}\text { Sangat } \\
\text { Tinggi }\end{array}$ & Dipakai \\
\hline 26 & Sukar & Rendah & Dipakai \\
\hline 27 & Sedang & Cukup & Dipakai \\
\hline 28 & Mudah & Cukup & Dipakai \\
\hline 29 & Sedang & $\begin{array}{l}\text { Sangat } \\
\text { Tinggi }\end{array}$ & Dipakai \\
\hline 30 & Sedang & Cukup & Dipakai \\
\hline 31 & Mudah & Cukup & Dipakai \\
\hline 32 & Sedang & Cukup & Direvisi \\
\hline
\end{tabular}




\begin{tabular}{llll}
\hline 33 & Sedang & $\begin{array}{l}\text { Cukup } \\
\text { Sangat } \\
\text { Tinggi }\end{array}$ & $\begin{array}{l}\text { Dipakai } \\
\text { Dipakai }\end{array}$ \\
35 & Sedang & $\begin{array}{l}\text { Cukup } \\
\text { Sedang }\end{array}$ & Dipakai \\
36 & Sedang & Cukup & Dipakai \\
37 & Sedang & Tinggi & Dipakai \\
38 & Sedang & Cukup & Dipakai \\
39 & Sedang & Rendah & Dipakai \\
40 & Sedang & Cukup & Dipakai \\
\hline
\end{tabular}

Setelah melakukan analisis lembar telaah soal yang telah diisi oleh 3 orang panelis, analisis tingkat kesukaran soal, dan analisis daya pembeda soal maka dapat disimpulkan bahwasanya terdapat 3 butir soal yang perlu direvisi sedangkan 37 butir soal lainnya sudah dapat dipakai. Adapun 3 butir soal yang perlu direvisi yaitu soal no: 3, 23, 32. Ketiga soal perlu direvisi berdasarkan hasil analisis validitas oleh ketiga orang panelis, tingkat kesukaran soal serta daya beda soal. soal no 3 dinilai valid namun memiliki tingkat kesukaran mudah, serta memiliki daya pembeda rendah sedangkan soal no 23 dan 32 dinilai tidak valid oleh ketiga orang panelis.

Indeks pengecoh (distraktor) soal dapat diketahui dengan menghitung indeks pengecoh dengan menggunakan Rumus menurut Zainal Arifin (2013:280), sebagai berikut:

$$
I P=\frac{P}{\frac{(N-B)}{n-1}} \times 100 \%
$$

Diketahui dari kelas $V I I_{1}$ sebanyak 35 (29\%) dari 120 distraktor berkualitas jelek atau sangat jelek, pada kelas $\mathrm{VII}_{4}$ sebanyak 39 (32\%) dari 120 distraktor berkualitas jelek atau sangat jelek, sedangkan pada kelas $\mathrm{VII}_{8}$ dari 120 distraktor terdapat $36 \quad(30 \%)$ distraktor berkualitas jelek atau sangat jelek. Dari ketiga kelas diperoleh rata-rata kualitas distraktor soal UTS matematika kelas VII SMP Negeri di Kota
Padang, dimana sebanyak 30\% distraktor belum dapat berfungsi dan perlu direvisi, karena masih berkualitas jelek atau sangat jelek, sedangkan selebihnya (70\%) distraktor lainnya sudah dapat berfungsi.

Distraktor pada soal UTS matematika kelas VII tingkat SMP Negeri di Kota Padang tahun 2016/2017 sudah dapat dinilai menjalankan fungsinya, yaitu untuk mempengaruhi peserta didik. Hal ini sesuai dengan tujuan diadakannya distraktor pada soal, seperti yang dikemukakan oleh Sudijono (2011:410) yang menilai tujuan utama dari pemasangan distraktor pada setiap butir item itu adalah agar dari sekian banyak testee yang mengikuti tes hasil belajar ada yang tertarik atau terangsang untuk memilihnya, sebab mereka menyangka bahwa distraktor yang mereka pilih itu merupakan jawaban betul atau distraktor dapat dikatakan berfungsi apabila sudah dapat mempengaruhi peserta didik

\section{SIMPULAN DAN SARAN}

\section{Simpulan}

1. Analisis terhadap kualitas butir soal yang ditinjau dari analisis validitas logis soal UTS matematika kelas VII tingkat SMP Negeri di Kota Padang tahun ajaran 2016/2017 terdapat 2 soal tidak valid, 7 soal memiliki validitas sedang dan 31 soal dengan validitas tinggi. Kualitas validitas empiris soal UTS matematika kelas VII tingkat SMP Negeri di Kota Padang tahun ajaran 2016/2017 adalah 0,49 dengan interpretasi validitas empiris tergolong sedang. 
2. Kualitas reliabilitas soal UTS matematika kelas VII tingkat SMP Negeri di Kota Padang tahun ajaran 2016/2017 adalah 0,64 dengan interpretasi reliabilitas tergolong cukup.

3. Analisis terhadap kualitas tingkat kesukaran soal UTS kelas VII tingkat SMP Negeri di Kota Padang tahun ajaran 2016/2017 dari 40 soal terdapat: 6 soal tergolong mudah, 30 soal tergolong sedang, 4 soal tergolong sukar.

4. Kualitas daya beda soal UTS matematika kelas VII tingkat SMP Negeri di Kota Padang tahun ajaran 2016/2017 dari 40 soal terdapat: 10 soal memiliki daya pembeda kurang baik, 14 soal memiliki daya pembeda cukup, 9 soal memiliki daya pembeda baik, 7 soal memiliki daya pembeda sangat baik.

5. Kualitas distraktor soal UTS matematika kelas VII tingkat SMP Negeri di Kota Padang tahun ajaran 2016/2017 diketahui sebanyak $30 \%$ distraktor belum dapat berfungsi dan perlu direvisi, karena masih berkualitas jelek dan sangat jelek, sedangkan $70 \%$ distraktor lainnya sudah dapat berfungsi.

Dengan hasil analisis dapat diketahui bahwasanya soal matematika kelas VII tingkat SMP Negeri di Kota Padang sudah berkualitas baik. Kualitas soal sangat penting dalam memperoleh informasi mengenai kemampuan peserta didik secara tepat. Oleh karena itu sangat diperlukan analisis soal sebelum diujikan kepada peserta didik agar peserta didik mendapatkan hasil yang maksimal. Setelah dilakukan analisis maka akan diketahui soal mana yang berkualitas baik, sehingga soal dengan kualitas baik dapat dijadikan dalam bentuk bank soal, dan dapat dipergunakan lagi sebagai rujukan dalam pembuatan soal untuk ujian selanjutnya.

\section{Saran}

1. Kepada pendidik

a. Soal-soal yang dibuat oleh pendidik matematika harus dikembangkan lagi secara meluas karena soal yang sekarang diujikan,walaupun memiliki validitas yang baik, namun juga harus memperhatikan komponen-komponen yang lain, yaitu keterampilan dan pengetahuannya sehingga nantinya peserta didik tidak hanya terpaku dalam satu bentuk soal akan tetapi pesertadidik akan mengetahui secara baik bentuk-bentuk soal pilihan ganda yang lain.

b. Sebelum soal diujikan kepada peserta didik, pendidik harus menganalisis soal tersebut terlebih dahulu, agar peserta didik mendapatkan hasil yang maksimal.

c. Pendidik mengetahui cara menganalisis soal sehingga bisa menjadi bahan acuan dalam memilih dan memilah soal-soal yang berkualitas.

d. Pendidik mempunyai bank soal matematika sendiri agar nantinya bisa merujuk soal-soal yang berkualitas untuk diujikan kepada peserta didik dimasa yang akan datang.

\section{Kepada Sekolah}

a. Mengingat pentingnya alat evaluasi untuk meningkatkan kualitas pendidikan maka alangkah baiknya setiap sekolah atau madrasah memiliki bank soal yang memadai.

b. Memberikan masukan dalam rangka meningkatkan kualitas alat evaluasi 
dengan cara memberikan panduan analisis kualitas soal mata pelajaran matematika khususnya dan mata pelajaran yang lain umumnya.

c. Soal yang sudah dianalisis dan hasilnya berkualitas baik dalam arti memiliki validitas soal, reliabilitas soal, derajat kesukaran, daya pembeda, dan distraktor dapat dijadikan sebagai kumpulan soal atau bank soal.

\section{REFERENSI}

Aliati dan Muchtar, Ibrahim. (2013). Kualitas Tes Ujian Nasional Matematika Siswa SMP Negeri Di Kabupaten Buton Utara Tahun Ajaran 2011/2012.

Amrin, Hermawati dan Busnawir. (2013). Kualitas Tes Buatan Guru Mata Pelajaran Matematika Kelas VII SMP 8 Baubau Tahun Ajaran 2012/2013.

Arifin, Zainal. (2013). Evaluasi Pembelajaran. Bandung: Remaja Rosdakarya.

Arikunto, Suharsimi. (2012). Dasar-Dasar Evaluasi Pendidikan. Jakarta: PT.Bumi Aksara.

Depdiknas Kota Padang. (2017). Juknis-analisibutir soal-isi-revisi_0104.

Hamzah, Ali. 2014. Evaluasi Pembelajaran Matematika. Jakarta: Rajawali Pers.
Mutmainah, Nafsul. (2012). Analisis Soal Ujian Akhir Sekolah Matematika Kelas IX SMP Se-Kabupaten Klaten Tahun Ajaran 2011/2012.

Putri,A.R. Analisis Tes Uraian Matematika Ujian Tengah Semester MTsN Punggasan Kecamatan Linggo Sari Baganti Kabupaten Pesisir Selatan Tahun Ajaran 2015/2016.

Sudijono, Anas. (2011). Pengantar Evaluasi Pendidikan. Jakarta: Rajawali Pers.

Sugiyono, (2012). Metode Penelitian Kuantitatif, Kualitatif dan $R \& D$. Bandung: Alfabeta.

Sukardi, (2011). Evaluasi Pendidikan Prinsip dan Operasionalnya. Jakarta: PT Bumi Aksara.

Supandi dan Farikhah, Lailatul. (2014). Analisis Butir Soal Matematika Pada Instrument Uji Coba Materi Segitiga.

Suryawati dan Yulfikar. (2012). Kualitas Tes dan Hasil Belajar Matematika Siswa Kelas VII SMP Negeri 9 Banda Aceh Tahun Ajaran 2011/2012.

Syahrial, Mohamad Arliyan. (2002). Karakteristik Soal Ulangan IPA Kelas II SLTP Kabupaten Hulu Sungai Selatan.Tesis S2. Yogyakarta: PPSUNY.

Sudijono, Anas. (2011). Pengantar Evaluasi Pendidikan. Jakarta: Rajawali Pers.

Thoha, Chabib. (1991). Teknik Evaluasi Pendidikan. Jakarta: PT Rajawali. 